\title{
SIGNA
}

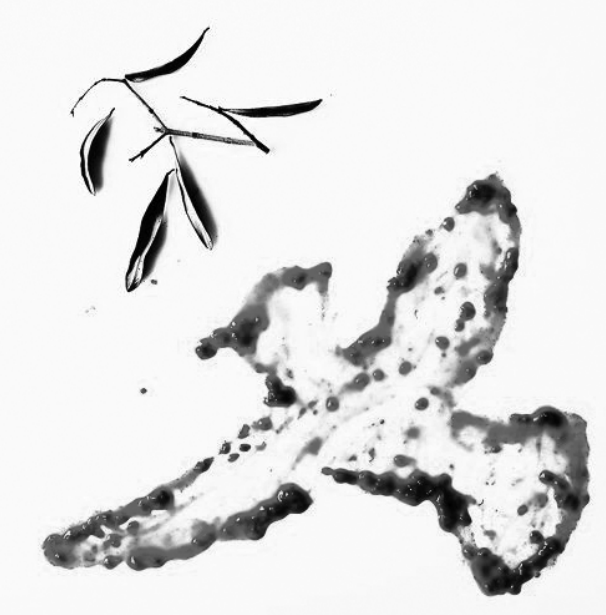

REVISTA DE LA ASOCIACIÓN ESPAÑOLA DE SEMIÓTICA

2011

20

CENTRO DE INVESTIGACIÓN DE SEMIÓTICA LITERARIA, TEATRAL Y NUEVAS TECNOLOGÍAS.

ISSN 1133-3634

UחED Editorial

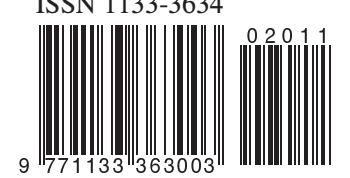

DEPARTAMENTOS DE LITERATURA ESPANOLA Y TEORÍA DE LA LITERATURA Y FILOLOGÍA FRANCESA

UNED 


\section{LA EDAD DE INTRANQUILIDAD: TERRORISMO Y EL FIN DEL SUEÑO AMERICANO}

\section{THE AGE OF ANXIETY: TERRORISM AND THE END OF THE AMERICAN DREAM}

\section{Candyce LEONARD}

Wake Forest University, USA

leonaca@wfu.edu

Resumen: El terrorismo del 11 de septiembre demostró una vulnerabilidad nunca conocido por los estadounidenses. Las dos obras teatrales del presente estudio plantean una América donde el Sueño Americano se ha hundido y donde quedan la melancolía y el anhelo por un pasado idealizado que parecía todopoderoso y libre de todo peligro.

Abstract: The terrorism of 9/11 revealed a vulnerability never before experienced by the United States. Both plays examined here depict a post $9 / 11$ country where the American Dream has collapsed, leaving in its place a sense of longing and melancholy for a romanticized past that felt powerful and safe from danger. 
Palabras clave: Teatro. Terrorismo. Sueño Americano. Luis Miguel González Cruz. Antonio Rojano.

Key Words: Theatre. Terrorism. American Dream. Luis Miguel González Cruz. Antonio Rojano.

Las dos obras teatrales analizadas aquí, Sueños de arena (2006), de Antonio Rojano (n. 1982), y Playback (2009), de Luis Miguel González Cruz (n. 1965), encarnan el período post 9/11: el día de los atentados contra las Torres Gemelas de Nueva York. Son dos obras de entre el mucho teatro español que responde a los atentados consecutivos en Nueva York (2001), Madrid (2004) y Londres (2005), y a la situación del terrorismo global cuando éste sobrepasó el espanto de muchos y llegó a personificar la violencia global de la primera década del siglo XXI. Pero no sólo es el mismo acto del terrorismo ni su impacto inicial lo que determina su carácter, sino el modo en que, como consecuencia, se desenvuelven y se transforman las perspectivas, actitudes y reacciones de sus víctimas, sus perpetradores, y los que observan desde lejos. Los dramas de Rojano y González meditan sobre los efectos del terrorismo que tuvo lugar en EE.UU., especificando que los ataques han anunciado el fin del Sueño Americano.

\section{EL SUEÑO AMERICANO}

«I believe in America. America has made my fortune», atestigua el emigrado italiano, don Bonasera, en el diálogo que abre el filme icónico de 1972, de Francis Ford Coppola, The Godfather, y estas palabras hacen que se desplieguen todos los deseos, fantasías, y pasiones que confluyen para crear el mito de América. El Sueño Americano, un sueño que resuena desde que los puritanos llegaron a las orillas del continente, puede significar incontables cosas. Según mucha gente, América ha sido el paraíso donde la vida es buena, donde se puede conseguir un buen trabajo, o donde se puede criar a los hijos con esperanza de un futuro optimista y seguro, con toda posibilidad de ser rico. Andrew Delblanco (1999: 61) resume la invitación de América: «Here was the ground of hope - the idea that Americans were not fixed in their circumstances of birth, but were free to become whatever they could imagine». Tal atractivo, después de la jerarquía tenaz del Viejo 
Mundo, aparecía como algo maravilloso. Además, Patrick J. Deneen (2002: 96) alude a la perspectiva del emigrado del siglo XVIII que quería huir de un mundo sin futuro hacia la «possibility of escape to new potentials, new freedoms, and new self-definitions that stands so invitingly and inexhaustibly in the American's future», posibilidades y libertades que se han descolorido en el siglo XXI. El concepto del Sueño Americano ha sido estudiado tanto en el campo académico como en el terreno popular por ser un tema que toca no sólo al mismo país, sino también a sociedades e individuos por igual. Joseph Cullen (2008: 5, 6) anota en la polémica sobre el significado del Sueño Americano, en su aspecto superficial, cuando dice que éste «today appears to mean that in the United States anything is possible if you want it badly enough», pero insiste en que «in the twenty-first century, the American Dream remains a major element of our national identity. [...] Explicit allegiance, not involuntary inheritance, is the theoretical basis of American identity».

Mientras Cullen se refiere a la identidad estadounidense y a su sociedad sin clases sociales rígidas, para David Kamp (2009: 118), el problema es cómo ha evolucionado el concepto del Sueño Americano: «What needs to change is our expectation of what the dream promises - and our understanding of what that vague and promiscuously used term, the American Dream, is really supposed to mean». Los dos imperativos de Kamp - el cambiar nuestra expectativa, y determinar el significado del concepto- son fundamentales, y explican por qué basta con pasar por el catálogo de una biblioteca o una librería para encontrar una lista larga de estudios, ensayos, literatura, etc., sobre el Sueño Americano, entre los cuales figuran libros como Restoring the American Dream, de Robert J. Ringer, 1979; Economic Freedom and the American Dream, de Joseph Shaanan, 2010; Family, Drama, and American Dreams, de Tom Scanlan, 1978; Cynicism and the Evolution of the American Dream, de Wilber W. Caldwell, 2006; Reclaiming the American Dream, de Richard C. Cornuelle, 1965, Facing Up to the American dream: Race, Class, and the Soul of the Nation, de Jennifer L. Hochschild, 1995; y Financing the American dream: A Cultural History of Consumer Credit, de Lendol Glen Calder, 1999.

Esta breve muestra de estudios pone de relieve la riqueza de perspectivas que cubren más de un medio siglo, investigando o teorizando qué es y cómo funciona el Sueño Americano; sin duda, la crítica en contra del mismo ha sido mucha, y las recetas para salvarlo son cuantiosas. A finales de 2008, José Luis Madrigal (n. 1957), un madrileño que vive en EE.UU. desde los finales de los ochenta, y profesor de la Universidad de la Ciudad de Nueva 
York, opina que «el sueño americano es una gran mentira y por eso no tiene mucho sentido preguntarse si está llegando a su fin, dado que nunca ha existido. [...] Fue un eslogan acuñado en los años treinta durante la depresión por algún listillo para ilusionar al personal» (Armada, 2009: 32). El listillo a que Madrigal se refiere es James Truslow Adams, autor de The Epic of America (1931). Si el cierre del siglo XIX dio al traste con las fantasías románticas de colonizar el Oeste, y de ser dueño de tierra de este mismo Oeste, y ser rico, entonces el fin del siglo XX ciertamente acabó con la idea mítica de una asequibilidad ilimitada de cosas materiales, de la virtud de tales posesiones, y de merecerlo todo.

Cuanto más sufre la economía global, más querido y necesario aparece el mito del Sueño Americano. Pese a todos los defectos del sueño, Cullen (2003: 7) afirma que «simply having a dream has sustained, even saved, lives that otherwise might not be deemed worth living». Sus palabras repiten las de Henrik Ibsen en su obra de finales del siglo XIX, El pato silvestre. El personaje Dr. Relling le explica al über idealista Gregers la importancia de la mentira, o sea, del sueño: «Deprive the average man of his vital lie, and you've robbed him of happiness as well» (Ibsen, 1992: 203). George P. Elliott (1974: 491), sin embargo, condena el concepto:

Why do we Americans have to be so pompous and self-conscious? Whatever the people of Uganda and China are up to, they are doing it without benefit of the American Dream, or The Chinese Dream; and The Swiss Dream evokes nothing so much as a big cake with a sugar Alp on top. Phrases like 100 percent American, the American Dream, the American Way of Life have always made me itchy; I avoid them.

Pero el mito es poderoso y sigue dominante en EE.UU. y, como Cullen comprende, es una parte endémica de la identidad nacional. El estudio de Kathryn Hume analiza la ficción americana entre los años 1960 y 1990, incluyendo unas cien novelas, que, por una razón u otra, expresan un desengaño respecto al Sueño Americano: «For all the flash and energy of the narrative voices, a disconcerting amount of the fiction expresses bitter disillusionment with America and the American Dream» (Hume, 2000: 1). Hume observa que los novelistas americanos «frequently respond with anger or disillusion to the gap between the America they experience or see and the ideal America enshrined in founding documents and the American Dream» (2000: 266). El desengaño origina la oscura actitud de rencor e ira, sentimientos que faltan en las dos obras teatrales españolas del presente estudio. 
Nos equivocaríamos si pensáramos que por ser españolas no sienten ellos la misma angustia que sus homólogos estadounidenses; el mundo en que vivimos hoy es global y no el coto cerrado que era España durante los años del franquismo. González Cruz nació a finales del franquismo y creció en el período democrático, la Unión Europea, y la comunidad global, al igual que Rojano, nacido en 1982. Ven la crisis en EE.UU. desde lejos, pero no son indiferentes a los efectos de la situación. González justifica sus motivos para escribir Playback, insistiendo en que la suya «es una obra con un cierto trasfondo del sueño americano convertido en pesadilla, por eso estaba interesado en que fuera una obra bilingüe, español/inglés, como una obra hablada en el subconsciente del occidente, donde el sueño americano fue nuestro último mito» (González, 2008). Como se verá luego, el tono de Playback es melancólico, y Sueños de arena crea un ambiente sofocante y sin salida.

\section{SUEÑOS DE ARENA}

Dice el dramaturgo Antonio Rojano, en lo referente a si hay un nexo entre su obra sobre el fin del sueño americano y los ataques terroristas de 2001:

Creo que hay vínculos, ahora que lo pienso. Por ejemplo, el 11 de septiembre - desde un punto de vista extranjero y español- el atentado contra las Torres Gemelas es un instante donde el hombre común, el americano de a pie, se da cuenta de su vulnerabilidad frente al mundo, una vez que se une a él. Tal vez sea un cliché o una opinión foránea sin contrastar, pero existe la impresión fuera de EE.UU., de que el americano cree fervientemente en los ideales de su patria, la apoya en "guerras santas» que quizás no sean del todo justas, pero él ni siquiera se lo plantea. Cree en su modelo vital, económico, laboral, el modelo que le proporciona su nación y sus mecanismos de aprendizaje. Cree incorrectos - o absurdos - todos los otros modelos posibles, hasta tal punto, que algunos llegan a convertirse en enemigos: comunistas, islamistas, etc. El día que el americano recibe el ataque dentro de su territorio, se siente débil, vulnerable. Pienso que nacen preguntas dentro de sí mismos, preguntas que nacen también en aquellos que comprueban el fin del sueño americano. Estas preguntas refieren al miedo, a la amenaza, a la duda. La duda sobre el modelo en el que vive, la duda sobre los valores que te llevan a un lugar distinto del que pensabas (Rojano, 2010).

El autor elabora un escenario donde el sueño no funciona, y sitúa la acción de su drama en Moriarty, Nuevo México, un pueblo verdadero de menos 
de 2.000 personas. Según su alcalde actual, Ted Hart, Moriarty se llama la «Crossroads of Opportunity» (2010), pero en el caso de Sueños de arena Moriarty es un desierto fuerte, plano, y vacío, que, en vez de oportunidades, promete poco más allá de espejismos.

Titulado «Historia de los puentes fracasados», el prólogo de la obra en tres actos abre la acción e introduce los temas fundamentales que se desarrollan en los actos subsecuentes. Es una noche árida cuando dos jóvenes de unos veinte años han subido a la azotea de un motel que está en un plano más alto del escenario. Sentados en sillas plegables, Ian y Starky beben cerveza y hablan de un millón de cosas, como lo hace la gente que lleva años de amistad y aventuras desde su niñez. Es un derribado motel, propiedad desde décadas de la familia de Ian; la canción que «se escapa» del transistor que los chicos escuchan es, según las acotaciones, «una usada canción» (13) ${ }^{1}$. Es Nueva York, Nueva York, interpretada por Frank Sinatra, y que corresponde a las condiciones del motel que ha visto mejores días. Lo que indica la sensación de desengaño y abandono es el letrero de luces de neón que desde la carretera señala que el motel no es ningún oasis del desierto. Según las acotaciones, se escribe como «Mot_l Dazzl_ing» (13), su apariencia rota y descuidada apunta que cualquier destello que el motel - o el Sueño Americano- pudiera haber emitido en el pasado se apagó hace mucho tiempo. Ian se queja: «¿Sabes que el mundo, el auténtico, está más allá del desierto? ¡Aquí no hay nada interesante....!» (14). Ian insiste en que gente como Frank Sinatra nunca iría a «cementerios de cerdos, a lugares como Nuevo México» (15). Unos comentarios analíticos provienen de esta pequeña porción del diálogo.

El primero, es que Frank Sinatra puede escribirse entre comillas para señalar que es una ficción creada por su público y sus agentes, un ícono del célebre del mundo de espectáculo, exaltado por Ian y por numerosa gente de América y más allá de sus fronteras. La figura de Sinatra se refiere al mito del Sueño Americano, un éxito de público de dimensiones exponenciales, que conocía la célebre Nueva York, otro ícono y hasta cierto punto ficticio, y que brilló en Las Vegas, un lugar verdadera y literalmente deslumbrante. Cullen (2003: 177) señala que Frank Sinatra representa la clase del Sueño Americano que denota la celebridad y que es una función que no depende del carácter de una persona, sino de su personalidad, de su ser famoso. Sinatra pertenece a un pasado idealizado, que parecía todopoderoso y libre de todo peligro.

\footnotetext{
1 Todas las citas las tomo de la edición de la obra citada en la sección de Referencias bibliográficas.
} 
El segundo comentario que sugiere es que el diálogo plantea la urgencia de Ian de escaparse de Moriarty, una idea que se desarrolla en su conversación con Starky, y que también guarda relación con el título del prólogo, «Puentes fracasados». Cuando sale por el transistor la noticia de que el cuerpo del niño Bobby Franks, víctima de unos doce años de un pederastaasesino en serie, acaba de ser encontrado por la policía en Edgewood, un barrio a solo diez millas de Moriarty, Ian le narra a Starky una anécdota casi irreal sobre el niño. Un día cuando Bobby Franks tenía siete años, Ian lo vio «clavado en mitad del puente: solo, quieto, justo en el centro del universo» (22). Ian se dio cuenta de que el niño «también soñaba con salir de aquí» (23), pero no pudo, y ahora está muerto, igual que las muchas chicas que, según el abuelo de Ian, se suicidaron por saltar del puente Kane, el mismo puente que Ian y Starky miran en la distancia de la noche. Fue durante la Segunda Guerra Mundial, cuando desesperadas y abatidas por los muchos chicos del pueblo que habían muerto luchando en la guerra y jamás regresaron, las jóvenes, incluso niñas, buscaron una salida en la muerte. Cuenta Ian, que «ahora lo llaman el puente fracasado» (21), y es patente la pesadilla que están viviendo.

En tercer lugar, el diálogo de Ian sobre Bobby Franks no solo insinúa una muerte en edad temprana en el pueblo de Moriarty, una vida abortada literal y figurativamente, sino que, también, el espantoso homicidio contrasta con el mito reluciente de Frank Sinatra, un mito que no se corresponde con la realidad sórdida sin remedio de esa vida sin salida que Ian considera que es Moriarty. $\mathrm{O}$ sea, el puente no funciona, no se puede cruzar a la tierra prometida. El prólogo despliega un contexto sombrío, pero al autor no le falta un sentido de humor. Cuando Ian habla del mutuo deseo de ver a Frank Sinatra, Starky, sorprendido, le responde que ya «Frank Sinatra está muerto», a lo que Ian grita «iQué cabrón!» (26), como si, para él, esto fuera la última crueldad. El mito muerto. El Sueño Americano muerto.

La transición del prólogo al primer acto y a sus personajes es otro momento de humor, y de desprecio hacia lo americano: un coche, visto antes como algo magnífico. Ian y Starky pueden oír el acto sexual de la pareja que ocupa la habitación situada justamente debajo de la parte de la azotea donde ellos están. Ian los ha visto llegar al motel aquella tarde en un decrépito coche, que, según Ian, «Lo llevaban resoplando como un viejo caballo» (25). Es un Plymouth amarillo, del que Ian se burla: «Tío, recuérdame que nunca ponga las manos sobre el volante de un Plymouth. Y menos si éste es amarillo» (25); el pobre coche que va resoplando nos hace pensar en Rocinante, 
el modo de viajar de otro soñador, y en las palabras duras del conocido novelista Henry Miller, que «The automobile stands out in my mind as the very symbol of falsity and illusion» (1945: 33). Es otro signo, como el letrero de neón, de un ícono deshonrado de una promesa insatisfecha.

El hecho de que los jóvenes escuchan y comentan el acto sexual de la pareja, que después comprobaremos, fue la violación de Vivien por Erie. Lo que los jóvenes oyeron - acto que tiene lugar en el propio drama - refleja que el tiempo no es lineal sino que da saltos. El montaje que Rojano hace del tiempo es el que sostiene el mundo de realidad/fantasía en el que sus personajes viven. En la Nota de autor, que precede al drama, Rojano propone desestabilizar la realidad: «las escenas que combinan fantasía y realidad [...] deben ir encaminados a confundir y embaucar al espectador. Los sucesos [...] son reflejos distorsionados, grotescos en ocasiones, propios de la noche amenazante en que se producen, de unos personajes impulsados por el instante que les ha tocado vivir» (2006: 11). El objetivo es plasmar un mundo tan ilusivo y elusivo como es el Sueño Americano, y hay más peso simbólico que realidad de carne y hueso.

Titulado «El hombre que mató a Joe Montana», la acción del primer acto se desarrolla en la noche que Vivien y William pasan con Erie en la habitación situada debajo de donde están Ian y Starky. Son ellos, a quienes Ian y Starky escuchan, los que protagonizan el resto del drama, y quienes sufren la misma situación existencial. El medio físico del desierto y el motel decadente es una exteriorización de la condición espiritual de los personajes. Es evidente que Vivien está rota psíquicamente, y que William quiere de todo corazón ayudarla; pero aquello, como el humilde Plymouth amarillo, no funciona, lo que se refleja no sólo porque fracasa en su intento ayudarla, sino también porque es incapaz de protegerla: es William el que hace el acuerdo con Erie para que éste violara a Vivien a cambio de llevarlos a Oklahoma. La conversación fragmentada de la pareja es mimética en vez de literaria, o sea, que inmediatamente revela sus preocupaciones y confusión. La inestabilidad psíquica de Vivien y la urgencia de William por suavizar su miseria y su miedo hace a la pareja susceptible de buscar la redención en algún milagro, y ponerse al alcance de los depredadores que tienen toda clase de trampa, violación, o engaño que infligirles. Vienen de California, tal vez huyendo como quiere hacerlo Ian, esperando ir a Oklahoma, y aquí el autor hace referencia a la novela kafkiana de 1911, Amerika.

En la novela Amerika, el Teatro de Oklahoma es el símbolo de salvación, que el protagonista, Karl, busca. El Teatro es la solución para todos los sin 
trabajo, pero al final de la novela, y sin aviso alguno, Karl desaparece. Richard Heinemann ve el Teatro de Oklahoma de la novela como un vehículo burocrático que «performs the salvific function of assigning appropriate work to a collective of lost souls». Entonces, para Heinemann, el Teatro de Oklahoma es un tipo de «utopian worker's community» (1996: 261), una solución - o sueño - para la gente sin recursos. Pero tal utopía no existe, como sugiere Alfred Wirkner, que piensa que Amerika es una novela comprometida; el académico opina que «the report of Karl Rossmann's fate is an example of a widespread anonymous fate that befalls many people in the same situation insofar as they trust the American Dream and its promises of a rapid social climb» (Hughes, 1981: 170).

El estado de Oklahoma contiene una gran ironía literaria, teniendo en cuenta que el Oklahoma Land Rush of 1893 fue la última oportunidad de conseguir tierra gratis y, en consecuencia, el Oklahoma Land Rush es un símbolo del borde de la frontera y el final del mundo libre. La gran promesa del Nuevo Mundo fue la tierra sin límite donde tuvieron cabida muchas utopías de carácter distinto. Además, unas décadas después del Oklahoma Land Rush, Oklahoma se convirtió en la Dust Bowl de los años treinta, el suceso histórico que sirve de tema de la novela del laureado con el Nobel John Steinbeck, The Grapes of Wrath (1939). Sus personajes, los Joads, tienen que salir de Oklahoma debido a la pobreza irremediable económica y espiritual que el país sufría, y van a California, precisamente el viaje al revés del que Vivien y William hacen en la obra de Antonio Rojano. William y Vivien esperan encontrar en Oklahoma una conocida institución para gente como Vivien; para ella sería una zona de seguridad contra un mundo cruel, y para William, llevar a Vivien a una utopía es un acto de humanidad que da sentido a su mundo. Pero tal lugar de tranquilidad y equilibrio no existe en ninguna parte. Es como el mundo «auténtico» que Ian cree que existe «más allá del desierto», un espejismo nacido de la desesperación, y de la esperanza de que el mundo no esté tan mal. Justo antes del oscuro final y después de una noche de violencia, Vivien entiende: «Ya no iremos a Oklahoma, ¿verdad?» (89). Con estas pocas palabras, Vivien pronuncia la derrota de su vida.

Literalmente, no van a Oklahoma porque el hombre que los iba a ayudar fue asesinado por Ian. El muerto, Erie, cuyo nombre en inglés es homónimo de la palabra eerie, que significa lo espeluznante, representa el desengaño, el fin del sueño, americano o de cualquier otro tipo. Tiene el talento de parecer sincero, pero es un lisonjero y timador que pronto revela su oscuro carácter. Es el violador de Vivien, cuyo acto de violencia los jóvenes Ian y Starky oyen al final del prólogo, y probablemente Erie es el pederasta al que la po- 
licía busca, y que ahora ha matado al hermano menor de Ian. Pero dentro de esta realidad borrosa, realmente no importa que lo sea o no. Por el hecho mismo de su agresividad, Erie es también perdedor de sí mismo metafóricamente, y literalmente por perder dinero en el juego. Es Erie el que quería matar a Joe Mantana, con lo que se enlaza con el título del primer acto. En 1979, tuvo lugar la célebre jugada entre Joe Montana y Dwight Clark que hizo que los Forty-niners ganaran el partido en sus últimos segundos ${ }^{2}$. Sucedió que Erie había apostado unos mil dólares por los Dallas, y perdió todo. Sin embargo, con el asesinato del supuesto liberador de Vivien y William, por muy merecido que fuera, se esfumó también toda posibilidad de llegar a la tierra prometida de Oklahoma.

Dentro de la acción, además de personajes vistos por el público, hay otros no vistos, pero cuyas historias el diálogo narra, y estos personajes muertos son tan importantes como los vivos. Los jóvenes soldados muertos en la Segunda Guerra Mundial, por ejemplo, y sus novias que se suicidaron, cuya historia Ian rememora, y el niño Bobby Franks, también muerto, aunque en este caso por mano de un pederasta, un degenerado de la peor categoría. Todos viven en la memoria colectiva del pueblo y sirven para dar la sensación de que Moriarty lleva una vida detenida, sin futuro. En el Tercer Acto, «Metempsicosis de Hamlet Chikatilo», sin embargo, son dos imágenes superpuestas «En el oscuro, proyectadas sobre el escenario» (80), personajes visibles, pero no vivos, en el escenario. Una es del vil homicida en serie, el ruso Andrei Chikatilo, y la otra el rostro de un cadáver cuya identidad no conocemos. Es cierto que la función de la proyección depende de la capacidad del espectador para reconocer a Chikatilo y poder encontrar el hilo que conecta el homicida ruso y el cadáver con el pederasta y Bobby Franks. La otra es cuando Vivien, al ver sangre por toda la habitación y el baño, dice: «Ser o no...» (80), y otra vez, la alusión depende de su reconocimiento por el espectador del soliloquio de Hamlet, tan profundo en su meditación sobre lo brutal que es la vida. Es evidente que otro vínculo entre Vivien y Hamlet es la locura, y como no sabemos si Hamlet ve el espectro de su padre, tampoco podemos fiarnos en que Vivien ve la sangre.

Es largo, como el de Hamlet, el soliloquio de Vivien que precede a la entrada de Erie. Pronto la tipografía de la obra escrita cambia para que las mayúsculas y el punto, el signo de puntuación que nos dirige en la conversación, desaparezcan del diálogo de Erie, y funcione en otro nivel:

${ }^{2}$ Se puede ver la famosa jugada, a la que Rojano se refiere, en la página: http://www.youtube. com/watch? $v=d-L m P F H g E 3 k$. 
VIVIEN. - ¿Quién es usted...? ¿Dónde está Willie?

ERIE.- Creía que estabas dormida parecías una muerta.

VIVIEN. - ¿Dónde está mi marido?

ERIE.- Morir dormir.

$[\ldots]$

VIVIEN.- ¡Haga el favor! ¿Quién es usted? ¿Qué hace toda esta sangre aquí?

ERIE.- Soy un violador acabo de violarla acabo de hacerlo y no lo recuerda (Ríe sin razón.) (81-82).

Como se indica, la representación depende del director y el actor, pero para el lector la confusión del diálogo esclarecedor es totalmente correcta en este mundo difuso. No sabemos si la conversación ocurre, o si se da en la imaginación de Viven; tal violencia le es impensable a Vivien y el olvido la salva.

Ian escucha el ruido, entra, y concluye que Erie es el pederasta que acaba de matar a su hermano menor que permanece muerto en el baño; no importa que sea o no. Es una vida desquiciada y una obra de tema esencialmente trágico donde la gente busca una ilusión, pero no encuentra, la ilusión que encarna Joe Montana. El entretejido de la fantasía y la realidad que Rojano utiliza para dar forma a la fragmentación del Sueño Americano es una estrategia que confunde la anécdota, pero sin estorbar el discurrir de la narración. El esclarecimiento no hace falta y, de hecho, no explicaría toda la ruptura que innumerables sociedades globales han conocido en el siglo XXI.

\section{PLAYBACK: LAS TORRES GEMELAS}

La acción del drama histórico Playback se centra en la vida y la muerte de Johnny Thunders, un punk rocker de las bandas estadounidenses The New York Dolls y The Heartbreakers, muy populares durante los setenta y ochenta, de gira por todo el mundo. Señalar al personaje Johnny Thunders como protagonista, sin embargo, perdería el valor del drama como estudio sincrónico de un período dentro de la historia de un país. Johnny Thunders es un ejemplo de una condición cultural, de la innovación, del dinero abundante y, finalmente, de la catástrofe. El personaje Johnny Thunders se identifica con el sentimiento del final de una época a causa de la muerte del Johnny Thunders histórico, bajo circunstancias misteriosas en 1991, un dato que aparece en el drama. Para los historiadores de la música, los viejos punk rockers, 
y los especialistas de la cultura, Johnny Thunders definitivamente se asocia con el género de punk rock y el panorama de drogas que caracterizó aquellas décadas, con una actitud que sus proponentes consideraron de boga, nueva, e indiferente del modo más chic. El enfoque del estudio presente sobre Playback es investigar los íconos y anécdotas que González elige para narrar la defunción de un carácter distintivo dentro de la historia de la sociedad contemporánea occidental.

El drama de sesenta y cuatro cuadros breves se abre con la banda Johnny Thunders and the Heartbreakers entrando en escena, mientras que el Realizador controla la representación que está grabando para transmitir luego con sus señales: «iiiSilencio!!! iiiiAplausos!!!! iiii¡Dentro Playback!!!!!» $(93)^{3}$. Se nota inmediatamente el contraste entre los músicos «silenciosos» y el Realizador cuya «voz en off suena por los altavoces» (93). El poder que éste ejerce, plasmado en el aumento de su voz, que se indica en el texto mediante los signos de exclamación, señala la intensidad creciente del papel que el Realizador hace, como si se estuviera representando a sí mismo. El Playback es un método de actuación en el que la música está pre-grabada y el cantante tiene lip sync, una práctica no inusual en aquel período histórico, pero que incomoda a Johnny. Varias veces pide hacer otra toma, pero al Realizador no le importa, satisfecho como está de haber terminado la sesión tras haber aceptado lo inauténtico. Luego Johnny se queja: «Es de gilipoyas eso de los playbacks, pero más gilipoyez aún es que tú muevas los labios para que hable otro tío que, además, eres tú. Es como si tú abrieras la boca hoy, y hablaras tú ayer [...] ¿Qué clase de trampa es ésa? Una trampa hecha por ti mismo. Tú mismo te haces trampa. Yo mismo me hago trampas. Un gilipoyas hace trampas a otro gilipoyas. No me gustan los playbacks» (97-98).

El lip syncing y la reacción de Johnny ofrecen varios puntos de análisis. El primero, es la esterilidad de la escena: no hay contacto entre la banda y el Realizador, y el Realizador no es nada salvo una voz en off, una mecanización del ser humano que está en el proceso de crear un producto para vender, sin ninguna atención al arte de la música ni a los músicos. No hay conversación; la banda no dice nada, sino que finge cantar en respuesta al mandato, y el Realizador habla con palabras de significado pero que no requieren un interlocutor. El segundo, es que los aplausos enlatados refuerzan la mecanización/deshumanización del ser humano y la esterilidad de la actuación, creando un ambiente de un lugar ya sin vida. La pre-grabación de la canción

\footnotetext{
3 Todas las citas las tomo de la edición de la obra citada en la sección de Referencias bibliográficas.
} 
también mecaniza la voz humana, pero todavía peor es que priva a la banda de una actuación en directo y por ello una relación espontánea con un público, algo de mucha transcendencia que un dramaturgo como González conoce por propia experiencia. Existe la impresión, porque la tecnología está tan a mano, por muy sintética que sea, de que lo auténtico no hace falta. En tercer lugar, el lip syncing denota una ilusión que se critica por el personaje David, colega de Johnny: «Lip-syncing orders your rhythm; playbacks order your lips movements; playbacks dictate when you move your mouth, when you sing your song. Playbacks order everything if you are a big enough asshole to sing over a playback» (122). David resalta la inautenticidad del método; es como perder su voz y, así, su poder. Vale destacar aquí el carácter bilingüe de la obra para hacer hincapié en la relación arraigada entre EE.UU. y España. Los personajes son estadounidenses, pero la acción tiene lugar en Madrid.

Con la señal «iiiiiDENTRO PLAYBACK!!!!!», escuchamos en inglés el conocido éxito de 1974, Stranded in the Jungle, de The New York Dolls. La canción, aparentemente banal, tiene una letra penetrante. Un joven se escapa de sus apresadores en África para encontrar al llegar a casa a su novia con otro chico: «When I got to Lover's Lane I was almost dead / but my soul was gone» (94-95). Las referencias recuerdan la guerra Vietnam, los conflictos políticos en EE.UU. a finales de los años sesenta y al principio de la década siguiente, y lo poco que le quedó al soldado al volver de esta misma guerra. No hay ningún aire nostálgico hacia aquella época, sino una sensación de frustración y desastre nacionales y personales. Aunque las anécdotas son distintas, ambas obras Sueños de arena y Playback, evocan una sensación desoladora sin remedio, bien precisado con las letras, «but my soul was gone». En 1958 el escritor francés Eugène Ionesco elucidó la atmósfera de vaciedad. en la que cual sus personajes se deenvuelven: «The characters I have used are not fully conscious of their spiritual rootlessness, but they feel it instinctively and emotionally. They feel lost in the world, something is missing which they cannot, to their grief, supply directly» (171). Se ve precisamente este sentido de desarraigo espiritual en ambos dramas españoles por la confusión, el desagrado y, especialmente, la añoranza, como dice Ionesco, por algo que no pueden acertar a definir.

Las técnicas que González emplea para destacar la fragmentación social y personal son: el tiempo no lineal, la repetición de escenas y sonidos y la presencia mística de los cuervos. La primera escena se repite al igual que otras específicas: Johnny drogado, conversaciones sobre bandas históricas, la 
muerte de uno de los músicos, y la entrevista después de la muerte de Johnny con una madrileña con quien éste salió durante sus tres semanas en Madrid. Las repeticiones crean cierto ritmo en el drama, tal como lo hace la música, a la vez que parecen automatizados o programados como una pre-grabación que vuelve a sonar sin fin. Finalmente, podría deducirse que cada repetición es como un ensayo como si el rehacer produjera un buen resultado, como en el filme alemán postmoderno de 1999, Run, Lola, Run. La acción se repite tres veces, hasta obtener el resultado que más le gusta al protagonista, Lola. Es un instinto humano de querer otra toma, como quiere hacer Johnny. Nos acordamos que los personajes del auto calderoniano barroco, El gran teatro del mundo, piden un ensayo:

REY.- Mucho importa que no erremos / comedia tan misteriosa.

RICo.- Para eso es acción forzosa / que primero la ensayemos.

DISCRECIÓN.- ¿Cómo ensayarla podremos / si nos llegamos a ver / sin luz, sin alma y sin ser / antes de representar?

POBRE.- Pues ¿cómo sin ensayar / la comedia se ha de hacer? (Calderón, 1974: 54).

Claro que el Autor no les permite tal ensayo porque la vida sólo se vive una vez, y «se ha de acertar de una vez cuando es nacer y morir» (1974: 54). No sólo está el auto de Calderón escrito con una paleta moral semejante a la de los dramas españoles estudiados aquí, sino que suena en él la condición humana y existencialista que también subrayan Sueños de arena y Playback.

Rojano esclarece la frustración humana por «la duda sobre los valores que te llevan a un lugar distinto del que pensabas» (2010). En el siglo XXI y en pleno postmodernismo, la repetición de escenas en Playback con sus pequeños cambios no nos sorprende, aunque a pesar de rehacer las acciones, el resultado principal es el mismo. La lucha de los personajes para dar una coherencia y un sentido a sus vidas es existencial.

La acción de Playback tiene lugar a lo largo de varias décadas del pasado desde los finales de los años sesenta hasta los años noventa. El autor se aprovecha de unos íconos conocidos de aquellas décadas, Johnny Thunders y su música entre ellos. Pero el más destacado y pujante es el World Trade Center, un ícono corporativo de dimensiones globales. Puede afirmarse que sólo hay dos cuadros breves y aislados dentro de la narración de la vida y muerte de Johnny Thunders. Estos dos cuadros son el núcleo de la obra. For- 
man un documental inventado por el autor al estilo del $\mathrm{NODO}^{4}$ sobre la construcción física de los edificios, pero es intencional no decir nada sobre la brillantez estética y económica que el World Trade Center prometiera. Cada cuadro se titula «Construcción de las torres gemelas en Nueva York», y el primer trozo sale en el Cuadro 7, narrado por una voz en off:

El hombre busca la luz, el hombre busca el poder de Dios. En Manhattan, entre los años 1972 y 1973, se construirán las torres más altas de la isla. El arquitecto Minoru Yamasaki ha diseñado dos torres gemelas que crecerán una al lado de la otra, un símbolo de poder, de luz y de Dios. Mejor dicho, dos símbolos. Uno semejante al otro, uno espejo del otro. Imagen del otro. Un símbolo que se mira al espejo. El World Trade Center (99).

El énfasis en señalar que hay dos en vez de una torre sugiere el exceso que se asocia con el materialismo de los EE.UU. y sus deseos humanos y globales que no tienen límite.

Hacia el final del drama en el cuadro 56, la voz en off vuelve a decir:

El lugar elegido para la erección de las torres pertenecía originalmente a la Hudson \& Manhattan Railroad y estuvo ocupado durante muchos años por terminales ferroviarias. Cuando finalicen las obras, El World Trade Center se erigirá como el complejo de oficinas más grande del mundo. Las Twin Towers necesitarán 181.400 toneladas métricas de hierro para su estructura y unos cimientos de 23 metros de profundidad. El volumen de tierra excavada irá a parar al cercano Battery Park City. Las torres gemelas tendrán 23 elevadores expresos y 72 ascensores locales. Habrá 43.600 ventanas (167).

González Cruz no comenta más ni se refiere en ningún otro cuadro al tema de aquellas estructuras colosales ni a su relación totémica con el capitalismo y su dominio transnacional, pero el engreimiento del codicioso proyecto es patente. El tono del documental escuece y las heridas supuran todavía más desde que González comenzó a escribir el drama en el otoño de 2004, solo tres años después de la destrucción terrorista de la joya de la silueta de Manhattan, y sólo unos meses después del atentado en Atocha, en Madrid. Lo que vemos en el ámbito en que Johnny Thunders vive es el terreno post-terrorista, cuando el Sueño Americano de invencibilidad se ha rendido y lo que queda es la confusión y el anhelo de tener otro ensayo, o hacer otra toma.

${ }^{4}$ El NODO era un noticiero, cuyo acrónimo significa Noticiarios y Documentales, antes de la película que se proyectaba obligatoriamente en los cines españoles entre 1942 y 1981. 
Los efectos de los pasajes documentales, ciertamente acompañados de imágenes en una pantalla al fondo del escenario, se intensifican, debido al salto al pasado, antes de construirse las Torres, y el uso del tiempo futuro. Esta técnica literaria/teatral vincula los cuadros documentales histórica y cronológicamente a los finales de los sesenta cuando se construían las torres, un hecho que convierte la grandeza de la propuesta de ser el eje financiero del capitalismo - una mitología americana - que se transformó, como ya sabe el público, en una pesadilla. Antes de estallar las torres $-\mathrm{y}$ aún antes de construirlas - se consuma la destrucción del pasado: las estructuras ferroviarias deben ceder paso al World Trade Center. Es una historia conflictiva que tardó años en solucionarse:

For example, on July 24, 1962 the tenants of Hudson Terminal sued to block condemnation of buildings for the World Trade Center, while on August 9, 1962 the New Jersey Superior Court approved the Port Authority's acquisition of the Hudson \& Manhattan Tubes and Hudson Terminal (Klapouchy, 2008).

Desde principios del siglo Xx, el H\&M forma parte de la historia neoyorquina y es un modo de transporte que no solo sirvió al sector urbano, sino que unificó el país. Su eficacia, sin embargo, se había sobrepasado por modos urbanos más modernos, y por el World Trade Center cuyo significado España entendía plenamente ${ }^{5}$.

El dramaturgo español Juan Carlos Rubio, nacido en 1967 y contemporáneo por tanto de González, aclara que «los autores estamos profundamente marcados por la sociedad y el momento histórico con el que nos ha tocado apechugar. No sólo porque nuestras obras reflejen tal o cual acontecimiento [...] sino porque nosotros mismos, nuestros principios morales, el prisma desde el que creamos, vienen condicionados por lo que hemos visto, sentido» (Rubio, 2008: 6). Sin tener que buscar más allá de los últimos diez años, vemos que un buen número de dramas españoles tratan de cuestiones contemporáneas tales como la inmigración, la guerra, la sexualidad, el VIH/SIDA y el terrorismo. Dada la cronología del trabajo de González Cruz y las circunstancias sociopolíticas que distinguen los últimos treinta años, no sólo en Occidente, sino en todo el mundo, Playback es una digna elucidación de la agitación con la cual entramos en el siglo XXI.

\footnotetext{
5 Según la historia, el World Trade Center ya estaba en camino al principio de los sesenta: «Then on September 27, 1960 the Port Authority (under state pressure and real estate enticement in the form of the World Trade Center) formally reversed its refusal to invest in rail transit» (Klapouchy, 2008). Para más datos sobre la historia de H\&M, ver http://www.hudsoncity.net/tubesenglish/3-operatinghistory.html.
} 
Los detalles esmerados sobre las Torres Gemelas que el documental de González relata, acerca del peso de la cantidad de hierro, el número específico de ventanas y ascensores, y el espacio enorme de tierra que hay que excavar para poder montar las torres, es una estimulación visual que introduce la historia y cultura de una nación con enlaces globales. A pesar del carácter conciso e independiente de los dos cuadros, el World Trade Center es ciertamente medular en el tema del drama porque ya todos sabemos de su ruina abrumadora e impensable. Un motor global de la economía mundial, el World Trade Center se describe por datos que fríamente identifican su esencia de piedra y metal, robándole así cualquier atisbo de humanidad.

La memoria es inherente para la obra: la memoria de quién era Johnny Thunders, y cómo eran las décadas de finales del siglo Xx. Es posible que algunos de los espectadores se acuerdan de cuando el plan para la construcción de las Torres Gemelas salió por primera vez en las noticias, o se acuerdan del propio levantamiento del lugar con fotos aparecidas en noticiarios o a través de artículos de periódico. Sin duda, los espectadores, que no pueden olvidarse del atentado contra las Torres Gemelas, se acuerdan del día del desastre. Es un recuerdo cultural, un recuerdo político, un recuerdo social, y un recuerdo personal. Todos ellos cruzan las fronteras de los EE.UU. para transitar por todo el mundo occidental y llegar a todo el orbe. Playback se aprovecha de alusiones y referencias, como lo hace Sueños de arena, cuyo reconocimiento por el espectador construye el contexto de lo que era y ya no existe. La novia española, que pasa tres semanas con Johnny cuando éste está de gira en Madrid, le pregunta sobre otros cantantes:

JENNIFER. - ¿COnociste a Warhol y a Reed? ¿Te gustan los Doors?

El sonido de los cuervos oculta la voz de la fan. JENNIFER sigue interrogando a JOHNNY.

JENNIFER. - ¿JIMi Hendrix?

JOHNNY. ¿ ¿Hendrix?

JENNIFER.— ¿Te gustaba Hendrix? (11).

Es un uso por el autor de la ironía relativa a la cultura pop para hablar de la superficialidad de la celebridad que desaparece en una noche. A la vez, las alusiones culturales acentúan que la vida es efímera. El Jimi Hendrix inimitable se murió de una sobredosis en el año 1970, a la edad de 27 años. En otro momento, Johnny habla brevemente sobre su música con el célebre Jim Morrison de la banda famosa The Doors; Morrison también se murió de una sobredosis a la edad de 27 en el año 1971: 
JIM MORRISON.- ¿Es esto todo lo que tienes?

JoHNNY.- Jim Morrison... Sid Vicious... Nancy... Billy Murcia... Jerry Nolan... Janis Joplin... Joey Ramone, Andy Warhol... Bono... Brian Jones... Syl Sylvain ... Kurt Cobain... (137).

Reconocemos los nombres y la gente, unos ya muertos, otros ya envejeciendo, poniéndonos de relieve qué difícil es sobrevivir, o hacer bien la vida.

También escuchamos una canción de Blondie (Debbie Harry, n. 1945), Dreaming (Soñando), de 1979, interpretada espontáneamente en inglés por Jennifer, la novia madrileña de Johnny: «Dreaming is free. [...] Dream, dream, even for a little while / Dream, dream, filling up an idle hour» (116117). Otra canción es Heroin de Lou Reed (n. 1942). Reed no tiene ningún diálogo, pero está en el escenario interpretando su canción de los años sesenta, solo señalado por las acotaciones: «Lou Reed canta Heroin» (136). Las letras no salen en el texto, pero el espectador las escucha:

Away from the big city

Where a man cannot be free

Of all the evils in this town

And of himself and those around

Oh, and I guess I just don't know

Oh, and I guess I just don't know

Heroin, be the death of me

Heroin, it's my wife and it's my life

Because a mainline to my vein leads

To a center in my head

And then I'm better off than dead

Because the smack begins to flow

I really don't care anymore (Reed, 1974).

González incluye a estos dos cantantes notables del género, Blondie y Lou Reed, y sus canciones que hablan de la huida de una realidad llena de conflicto. Las letras se repiten en varios cuadros, y se suman a la tensión que producen los demás sonidos.

Los sonidos y la música fijan la condición emocional y la cronología de la acción, pero son los cuervos los que auguran desgracias y muerte de modo místico. Unas veces aparecen los pájaros mismos, otras veces escuchamos sus sonidos. Aparecen, según las acotaciones: «El sonido de los cuervos oculta la voz de la fan» (109); «Los cuervos graznan como si fueran 
espantados por la guitarra de JOHNNY» (110); «Los cuervos chillan y sobrevuelan la escena» (150). Los cuervos son para el público; los personajes ni los ven ni los escuchan, y componen una parte imprescindible de la obra con sus sonidos chirriantes y escalofriantes, y su presencia perturbadora. Se burlan cruelmente de nosotros con su aparición de rapiña y su apetito sempiterno y voraz, invadiendo nuestra existencia con el aviso de una pesadilla en espera de ser vivida. Son un indicio de un peligro inminente e inexorable.

La automatización final del ser humano cierra el drama en un círculo que nos lleva al comienzo de la acción, a través de una grabación que dura casi cuatro minutos:

JOHNNY THUNDERS AND THE HEARTBREAKERS entran en escena en silencio. Una voz en off suena por los altavoces.

REALIZADOR: iiiSilencio!!!! iiiiAplausos!!!!! iiiiiDentro Play-back!!!!!!

Aplausos enlatados. JOHNNY y su grupo comienzan a bailar y mover la boca. Hacen como que cantan «Stranded in the jungle», pero no suena nada. Todo está en silencio. Los músicos siguen perfectamente una coreografía y música imaginaria, pero no se oye nada, tan sólo se oye al ayudante de realización, FEDE, cantar las órdenes del playback (176).

FEDE.- Maracas, y al segundo tambores.

0’05» Aullidos contestado por guitarras.

0'09» Otro grito y guitarras.

0'12» Otro grito y guitarras.

0'19» Coro de hombres

0'22» Otra vez coro de hombres.

0’26» Canta solista contestado por guitarras.

Baterías de fondo

Solista y reefs guitarra

0'47» Batería y, al segundo canta.

0'48» Coro de chicas

0'52» Piano y guitarras

0'55» Canta estribillo el solista

0'59» Contesta coro chicas

1'01» Solista estribillo

I'05» Contesta coro chicas

I'08» Solista estribillo

1'15» Coro chicas y guitarras

1'18» Voz solista capella

1'21» Tambores y coro de hombres

1'28» Voz solista

Reefs guitarra alternando 
1'50» Batería y coros hombres

1'53» Batería

1'54» Guitarra y piano

1'58» Voz solista canta estribillo

2'01» Contesta coro chicas

2'03» Solista estribillo

2'07» Contesta coro chicas

2'09» Solista estribillo

2'16» Guitarras y coro chicas

2'20» Voz solista

2'23» Tambores y coro chicas

2'36» Voz solista

Alterna con reef guitarras

2'48» Voz solista

2'53» Reef guitarra

Voz solista

3'06» Guitarras

3'09» Voz solista estribillo

3'13» Contesta coro chicas

3'15» Voz solista estribillo

3'19» Contesta coro chicas

3'22» Voz solista estribillo

3'30» Contesta coro chicas

3'31» Voz solista estribillo

3'33» Contesta coro chicas

3'35» Voz solista estribillo

3'37» Contesta coro chicas

3'38» Voz

3'39» Coro chicas

3'40» Guitarras y final.

Termina la canción y suenan aplausos enlatados (176-179).

El poder consumista ha silenciado a los músicos; quedan como autómatas sin capacidad ni de cantar ni de hablar. Las órdenes controlan la acción sin ninguna resistencia, todo preparado y ejecutado, de modo no muy diferente a cuando los terroristas seguían las indicaciones previstas para todo lo que había realizarse tanto el 11-S como el 11-M. Playback, un estudio riguroso de la condición humana, es una elegía desconsoladora y una acción comprometida para narrar nuestra cultura social, y para inquietar la consciencia de los espectadores. 


\section{CONCLUSIÓN}

Punzadas de la añoranza y melancolía por algo ausente de la vida corren a lo largo de las dos obras. Sueños de arena y Playback reflejan los sucesos verdaderos $-\mathrm{y}$ a veces aciagos - del mundo que, en todas partes, centran la atención de los autores que escriben en nombre de la humanidad: la guerra americana en Irak, la crisis económica global, los vertidos del petróleo, el paro, el fundamentalismo religioso, las luchas rebeldes armadas, o el terrorismo que hace daño al prójimo. En el caso de los dramas del actual estudio, que, aunque centrados en la experiencia estadounidense si atendemos a la anécdota, es también la experiencia mundial del ser humano de cualquier país, porque el sueño de una buena vida es el sueño humano.

Es lógico que el atentado de 11-S, cuando EE.UU. sufrió una vulnerabilidad fatal, inspirara los dramas sobre la caída del Sueño Americano. No parece suficiente, sin embargo, para explicar el desengaño cuatro o cinco años después de la destrucción del World Trade Center, pero los acontecimientos de reacción al atentado, sí lo explican. La presente autora estaba en Madrid el 14 de febrero de 2003, la tarde en que en muchos países europeos tuvieron lugar manifestaciones contra la guerra en Irak, y cuando la crítica española contra al Presidente Bush fue palpable. Las cuestiones sobre la ética de la tortura y el papel de las libertades civiles siguen sin resolución, pero los efectos morales se sienten, y uno se pregunta hasta qué punto llegaremos y cuánto vamos a justificar para proteger a nuestro país. Se puede conocer un lado de la opinión pública en EE.UU. en este momento por programas televisivos como el Washington Journal, que permiten que la gente entre en el debate por teléfono. En un programa de junio de 2010, un Republicano de Wisconsin quería volver al modo de vivir de aquellos años: «If you look back at the 50s, 60s, 70s, and 80s, we had a life style we will never see again. [...] The oil spill definitely is a major problem, the wars are a major problem, but these are relatively short terms things. I think the true crisis today is the loss of the American life style» (2010). En vez de criticar al gobierno por la desilusión que sufre, el hombre de Wisconsin busca el Sueño Americano que él piensa que existía en aquellos años, ahora romantizados.

Otro punto de vista guarda relación con la política y la actitud del Presidente Bush cuando se examina la trayectoria de las secuelas del atentado y sus consecuencias. En su libro The Age of Anxiety. McCarthyism to Terrorism, que originó el título de este estudio, Haynes Johnson compara McCarthyism a lo que hizo Bush por medio del miedo: «fear again contributes to a climate in which abuses of power, infringement of liberties, and perva- 
sive secrecy thrive» (2005: 4); «The McCarthyistic tactics of 2004 were more disturbing than those of half a century ago, for this time they were employed by the president of the United States» (2005: 495). «Prominent conservatives who dared question the wisdom of the rush to war in Iraq were also accused of being unpatriotic and of supporting America's enemy» (2005: 461). Visto que las palabras de Johnson no son de tal carácter que pueden verificarse empíricamente, hay otros datos que subrayan la disposición del gobierno $-\mathrm{y}$ de mucha gente dominada por el miedo y la ira - que marcan las acciones del período. Johnson cita la orden presidencial del 6 de noviembre de 2001 que entró en vigor sin ninguna notificación pública. Según esta orden, los enemigos «such as those imprisoned at the U.S. Guantanamo Bay base in Cuba could be denied basic guarantees of American justice: the right to a lawyer; the right to a public trial; the right to remain silent; the right to a presumption of innocence; the right that one's guilt be proven beyond a reasonable doubt» (473). Poco después, otra orden, del 13 de noviembre de 2001, «allowed for closed trials - trials in which a simple majority could sentence a defendant to death» (473). Más que nada es la anulación de los derechos civiles, por no decir de los derechos humanos los mismos derechos que habían sido el sello distintivo de los EE.UU. y punto fuerte de crítica cuando no se cumplieran en cualquier otro país -, lo que constituye el fin del Sueño Americano.

Desde este punto de vista, el abismo, la melancolía y la intranquilidad que impregnan el teatro de González Cruz y Rojano se enlaza ciertamente con el terrorismo, pero más aún con los hechos del gobierno de los EE.UU. que son un anatema irreconciliable con la idea de justicia y libertad. Con todo y con eso, el Sueño Americano persiste; se ve que actualmente, el proceso de identificar y sostener el concepto sigue. En 2009, William Greider propone solucionar la crisis:

Here is the grand vision I suggest Americans can pursue: the right of all citizens to larger lives. Not to get richer than the next guy or necessarily to accumulate more and more stuff but the right to live life more fully and engage more expansively the elemental possibilities of human existence (2009: 12).

Greider apunta a la necesidad de algo que nos ayude a aguantar las realidades, que en ningún siglo ni en ningún lugar, han sido todas buenas, a la vez que plantea, tristemente, un sueño abstracto difícil de realizar a un nivel extenso. No sabemos qué es «larger lives», ni cómo conseguirlas. De hecho, Mirco Mankel resalta la abstracción del término Sueño Americano cuando cita la Westdeutscher Rundfunk del año 1979: 
The expression is increasingly used by politicians who, by invoking the abstractions behind it, of which everyone is more or less clearly aware, try to win the confidence of the American electorate. The more frequently it is repeated and the more widely the contexts in which it is used differ, the more difficult it becomes precisely to determine its meaning. What it lacks in precision it gains in emotional appeal (1979/2009).

Por más precioso y querido que haya sido el mito del Sueño Americano, y por más que viva en el alma de tanta gente, en el siglo XXI, todavía más que en el año 1979, es una abstracción que se puede utilizar tanto de manera rastrera como salvadora. El escritor norteamericano, Joe Bageant, no nos plantea ninguna solución, sino que subraya el hecho de que en verdad no se sabe qué hacer, del mismo modo que Vivien y William se quedan sin un desenlace, y Johnny Thunders está muerto. Es un momento de impotencia cultural de los EE.UU.: «So here we are, sleepwalkers in the intellectual and spiritual desert of America, 2004, at the end of the Enlightenment. We are literally dying for the lack of a new idea to animate our culture, government and the national mind» (2004: 6). Bageant resalta que la vida está detenida.

González Cruz y Rojano aciertan en identificar el fin de una época de experiencias y propósitos específicos como Bageant enuncia, pero podríamos argüir que todas las épocas están inmersas en el proceso de desarrollarse o terminar. El Sueño Americano es un mito, pero otro y más grande es la creencia de que el Sueño Americano terminó. El problema es que ya no se ha vuelto a construir en el siglo XXI. El encanto de una tierra prometida permanece, pero la capacidad de innovarlo dentro de las realidades tanto de la nación como de la comunidad global está cada vez más lejos de nuestro alcance. Christopher Jencks (2008: B6), determina que reformar el Sueño Americano depende del partido político que domine en un momento dado y sin duda tiene razón. Seguimos esperando.

\section{REFERENCIAS BIBLIOGRÁFICAS}

ARMADA, A. (2009). El Sueño Americano. La Coruña: Ediciones del Viento.

BAGEANT, J. «Sleepwalking to Babylon».www.coldtype.net/Assets.04/Essays.04/Sleep.pdf.

DELBLANCO, A. (1999). The Real American Dream. A Meditation of Hope. Cambridge, MA: Harvard University Press. 
CALDERÓN DE LA BARCA, P. (1974). El gran teatro del mundo, Eugenio Frutos Cortés (ed.). Madrid: Cátedra.

DENEEN, P.J. (2002). «Awakening form the American Dream: The End of Escape in American Cinema?». Perspectives on Political Science 31.2, 96-103.

ELLIOTT, G.P. (1974). «Waking from the American Dream». The Nation, Nov. 16, 491-92.

GONZÁLEZ CRUZ, L.M. (2008). Comunicación por correo electrónico, 27 de octubre.

- (2009). Playback. Madrid: Teatro del Astillero.

GREIDER, W. (2009). «The Future of the American Dream». The Nation, May 25, 11-16.

HART, T. (2010). «Welcome to the City of Moriarty Website». http:// www.cityofmoriarty.org/.

HEINEMANN, R. (1996). «Kafka's Oath of Service: Der Bau and the Dialectic of Bureaucratic Mind». PMLA 111.2, 256-70.

HUGHES, K. (1981). «Review: Kafka Research 1974-1979: A Report». Reviewed works: Namen und ihre Bedeutungen im Werke Franz Kafkas: Ein interpretatorischer Versuch by Elizabeth M. Rajec Franz Kafka: Kunstprobleme by Todd C. Hanlin Franz Kafka: Eine Aufsatzsammlung nach einem. Symposium in Philadelphia by Maria Luise Caputo-Mayr. New German Critique 22, «Special Issue on Modernism», 163-183.

HUME, K. (2000). American Dream/American Nightmare. Fiction Since 1960. Chicago: University of Illinois Press.

IBSEN, H. (1992). The Wild Duck. [Trad. Rolf Fjelde]. New York: Penguin.

IONESCO, E. (1957). «The World of Ionesco». International Theatre Annual 2: 171, Calder, London. Citado en Drama in the Modern World: Plays and Essays, Samuel A. Weiss (ed.), 48-81. Lexington, MA: D.D. Heath and Company, 1964.

JENCKS, C. (2008). «Reinventing the American Dream». The Chronicle Review, Oct. 17, B6-B8.

JOHNSON, H. (2005). The Age of Anxiety: McCarthyism to Terrorism. Orlando: Harcourt. 
KLAPOUCHY, B. (2008). «Operating History». http://www.hudsoncity.net/ tubesenglish/3-operatinghistory.html.

KEMP, D. (2009). «Rethinking the American Dream». Vanity Fair http://www.vanityfair.com/culture/features/2009/04/americandream200904.

WESTDEUTSCHER RUNDFUNK (1979), citado por Mirco Mankel (2009), «American Dream Reference Page», en http://mankel.free.fr/AmericanDream/literary_overview.html.

REED, L. (1974). Heroin. http://lyrics.filestube.com/song/ a282e2e3fob136de03e9,Heroin.html.

ROJANO, A. (2010). Comunicación por correo electrónico, 3 de marzo.

- (2006). Sueños de arena. Madrid: Centro de Documentación Teatral.

RUBIO, J.C. (2008). «¿De qué escriben los autores?». Las Puertas del Drama 32, 4-7.

WASHINGTON JOURNAL (2010). «How Presidents Respond to Crises». Transmitido por la televisión C-Span, el 6-VI-2010. http://www.c-spanvideo.org/program/293908-4. 